\title{
REVIEW
}

\section{Edwardsiella piscicida: a significant bacterial pathogen of cultured fish}

\author{
N. Buján, Alicia E. Toranzo, B. Magariños* \\ Departamento de Microbioloxía y Parasitoloxía, Facultade de Bioloxía-Edif, CIBUS, and Instituto de Acuicultura, \\ Universidade de Santiago de Compostela, Santiago de Compostela, 15782, Spain
}

\begin{abstract}
Edwardsiella piscicida, a Gram-negative, facultative aerobic pathogen belonging to the Enterobacteriaceae family, is the etiological agent of edwardsiellosis in fish and a significant problem in global aquaculture. E. piscicida has been reported from a broad geographical range and has been isolated from more than 20 fish host species to date, but this is likely to be an underestimation, because misidentification of E. piscicida as other species within the genus remains to be resolved. Common clinical signs associated with edwardsiellosis include, but are not limited to, exophthalmia, haemorrhages of the skin and in several internal organs, mild to moderate dermal ulcerations, abdominal distension, discoloration in the fish surface, and erratic swimming. Many antibiotics are currently effective against E. piscicida, although legal restrictions and the cost of medicated feeds have encouraged significant research investment in vaccination for the management of edwardsiellosis in commercial aquaculture. Here we summarise the current understanding of E. piscicida and highlight the difficulties with species assignment and the need for further research on epidemiology and strain variability.
\end{abstract}

KEY WORDS: Edwardsiella piscicida $\cdot$ Aquaculture $\cdot$ Fish disease $\cdot$ Edwardsiellosis

\section{INTRODUCTION}

The genus Edwardsiella belongs to the Enterobacteriaceae family based on biochemical characteristics (Brenner 1984), the presence of 'Kunin antigen' (Mäkelä \& Mayer 1976) and DNA-DNA hybridization with other genera belonging to the family (Brenner 1978). In the early 1960s, Edwardsiella was independently reported by several authors as a new group of Gram-negative rods, producing hydrogen sulfide, indole-positive and mannitol-negative. Sakazaki \& Murata (1962) described the 'Asakusa Group' of 256 enterobacterial isolates obtained from snakes with similar biochemical characteristics, while King \& Adler (1964) isolated a group of bacteria analogous to the 'Asakusa group' from a patient with gastroenteritis

*Corresponding author: beatriz.magarinos@usc.es assigning the name 'Bartholomew group'. Later, Ewing et al. (1965) described the species E. tarda from a new biogroup designated as 'biotype 1483-59', indicating the similarity of this species with the 'Asakusa' and 'Bartholomew' groups. At the same time, Hoshina (1962) described the species Paracolobactrum anguillimortiferum, the etiological agent of 'red disease' in eels. Sakazaki \& Tamura (1975) suggested the name Edwardsiella anguillimortifera to include isolates previously designated as E. tarda by Ewing et al. (1965) and as P. anguillimortiferum by Hoshina (1962). However, Farmer et al. (1976) detected differences in some phenotypic tests between both descriptions, validating E. tarda as a species.

Until 1980, the genus Edwardsiella contained only a single species, Edwardsiella tarda. Edwardsiella

() The authors 2018. Open Access under Creative Commons by Attribution Licence. Use, distribution and reproduction are unrestricted. Authors and original publication must be credited. 
hoshinae (Grimont et al. 1980) isolated from reptiles and birds, and Edwardsiella ictaluri (Hawke et al. 1981) isolated from channel and white catfish were then described. Recently, the novel species Edwardsiella piscicida (Abayneh et al. 2013) and Edwardsiella anguillarum (Shao et al. 2015), both comprising isolates recovered from diseased fish and previously classified as E. tarda, were identified. Reclassification of these isolates was based on contemporary genetic methods.

After its first description, identifications of E. piscicida were published exponentially. Moreover, genetic surveys of E. tarda isolates from historical reports concluded that many isolates previously classified as E. tarda actually belong to the species E. piscicida (Reichley et al. 2017, Buján et al. 2018b). This recent reclassification and review of archival data suggests E. piscicida is more problematic in global finfish aquaculture than E. tarda. The aim of this article is to compile the current knowledge of edwardsiellosis caused by E. piscicida, focusing on phenotypic, serological, and genetic characters, as well as putative virulence mechanisms of the bacterium. In addition, the geographical distribution, host species affected, diagnostic methods, and potential control or management strategies to prevent the disease are addressed.

\section{GEOGRAPHICAL DISTRIBUTION AND HOST SPECIES}

With the recognition of E. piscicida as a discrete taxon (Abayneh et al. 2013, Reichley et al. 2017, Buján et al. 2018b), it has become evident that E. piscicida has a global geographic distribution. The first report of mortality in cultured fish caused by E. piscicida (identified as E. tarda at the time), occurred in Japan in 1979 (Castro et al. 2011a). In recent years, epizootics have been reported in Northern and Southern Europe (the Netherlands, Norway, Greece, France, Spain and Portugal; Castro et al. 2006) as well as China, Japan and the USA (Matsuyama et al. 2005, Griffin et al. 2014, Li et al. 2017), causing enormous economic losses in the fish industry. While many of these descriptions occurred prior to the recognition of E. piscicida, recent genetic studies have tied these reports to current Edwardsiella systematics (Abayneh et al. 2013, Shao et al. 2015, Reichley et al. 2017, Buján et al. 2018a). At present, E. piscicida has been isolated from a wide range of fish species (Table 1). Although E. tarda is involved in human clinical infections, until now E. piscicida has not been reported as a zoonotic agent. However, Castro et al. (2011a) demonstrated that E. piscicida may be virulent for some homoeothermic animals based on pathogenicity assays carried out in mice.

\section{ISOLATION AND IDENTIFICATION}

E. piscicida grows on a variety of general growth media including, but not limited to, trypticase soy agar, brain heart infusion agar, Mueller-Hinton agar, Luria broth, and marine agar. Differential media for the Enterobacteriaceae such as MacConkey agar, xylose-lysine-desoxycholate agar and SalmonellaShigella agar, as well as Edwardsiella tarda agar (Lindquist 1991) which was designed for the specific isolation of E. tarda, are unable to differentiate E. piscicida from other members of the genus Edwardsiella (Castro et al. 2011b). Biochemical test results, especially for carbon utilisation, are variable. Thus, although some phenotypic tests occasionally provide differential results among E. piscicida and other members of the genus (Table 2), phenotypic analysis by such methods are not recommended for reliable discrimination between E. piscicida and E. tarda (Griffin et al. 2013). Similarly, the API 20E and the BBL crystal enteric/nonfermenter identification system codes for E. piscicida are similar to those for bona fide E. tarda (Reichley et al. 2017).

Fatty acid methyl ether (FAME) analysis was performed in order to determine if the Sherlock Microbial Identification System (MIDI) could be employed for the identification of E. piscicida (Castro 2011, Reichley et al. 2017). The MIDI system misidentified E. piscicida as E. tarda based on species profiles populating the library's database. However, a dendrogram constructed with the MIDI Sherlock software (Fig. 1a) which determines relatedness between species through Euclidean distance, clustered E. piscicida separately from E. tarda and affords discrimination between species (Castro 2011). Therefore, it is suggested the fatty acid profiles of this species be deposited within the Sherlock Microbial Identification System database to validate its application in the identification of E. piscicida. In addition, the 2D plot of principal components (Fig. 1b) revealed 4 groups, 3 of them encompassing European isolates (group I, II and III) while Asian and American strains formed a different group (group IV).

Matrix-assisted laser desorption/ionization time of flight mass spectrometry (MALDI-TOF MS) has also been used for the identification of a collection of E. piscicida strains obtained from different host and 


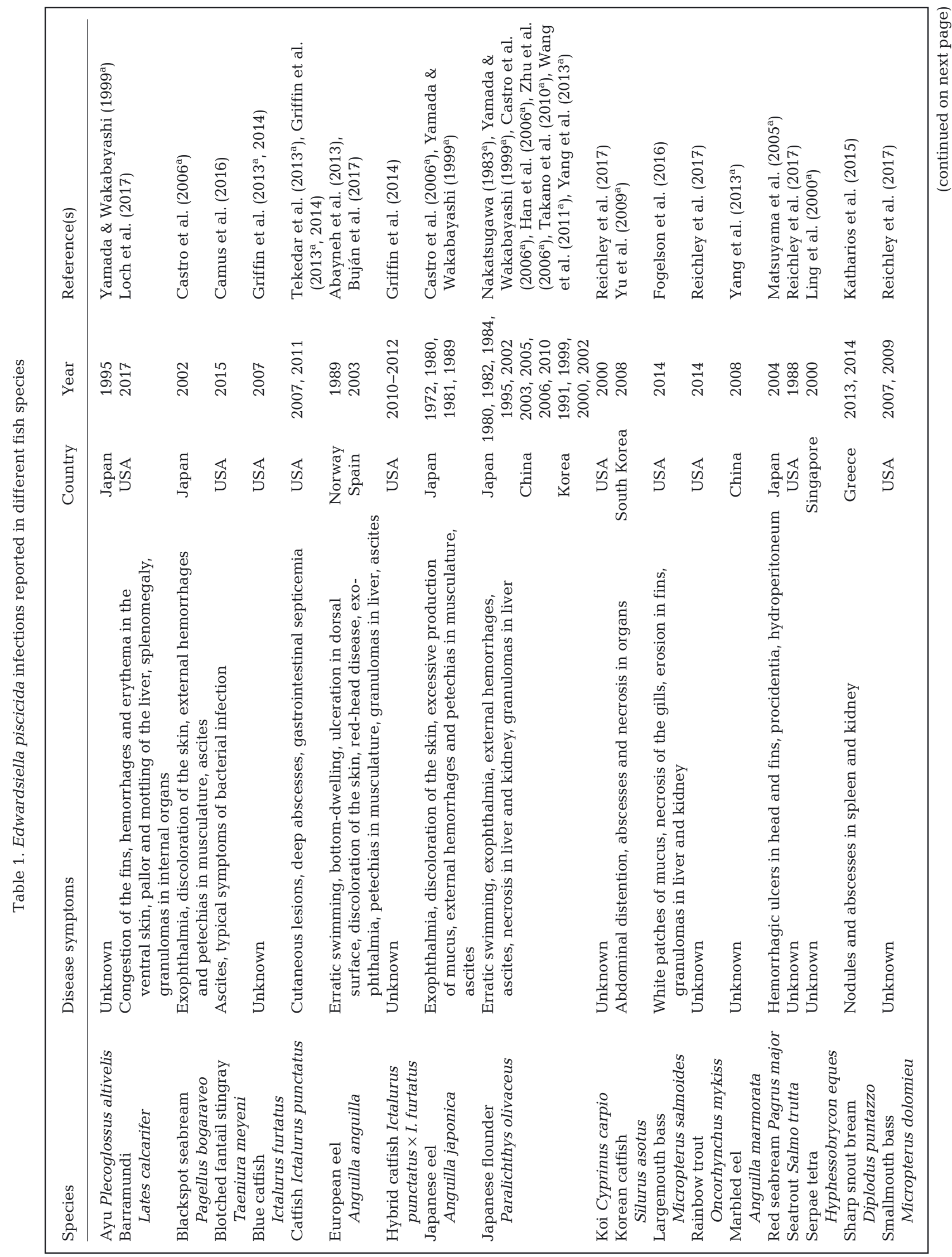




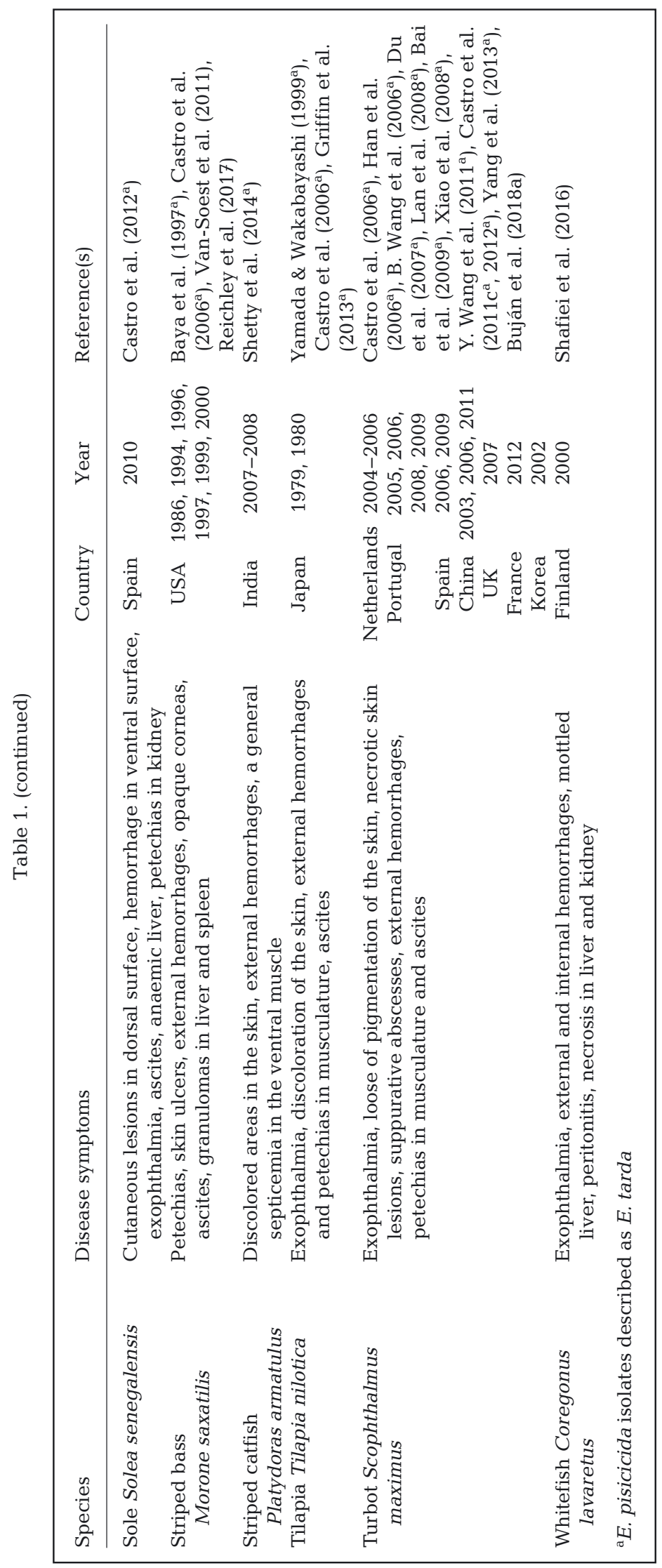

origins. Although the existing database misclassified the strains of E. piscicida as E. tarda, specific mass spectra fingerprints were observed for each species due to inherent differences in the cellular proteins expressed (Barja et al. 2008, Fogelson et al. 2016, Reichley et al. 2017). The incorrect assignment of these strains as E. tarda is attributed to the fact that the reference protein mass spectra database was compiled prior to the recognition of E. piscicida as a species, resulting in outdated identification of the strains included in the database. In fact, the protein profiles included in the database of the strains ACC35.1, ACC36.1 and HL23.1, which have since been identified as E. piscicida, are categorized as E. tarda in line with their original designations (Buján et al. 2018b).

Lastly, polymerase chain reaction (PCR) protocols were developed for a rapid and specific identification of Edwardsiella species from pure cultures and fish tissues. Different pairs of primers designed to target the haemolysin gene (tardaF/tardaR; Chen \& Lai 1998), the type 1 fimbrial gene cluster (etfA and etf $\mathrm{D}$; Sakai et al. 2007) or the gyrB gene (gyrBF1/gyrBR1; Lan et al. 2008) can differentiate E. tarda and E. piscicida from other members of the genus. Griffin et al. (2014) developed E. piscicida-specific PCR primers based on the work of Sakai et al. (2009), and Reichley et al. (2015b) used these speciesspecific primers in the development of a realtime PCR (qPCR) assay to provide a rapid, quantitative confirmatory test for this microorganism. This qPCR assay has since been used in a multiplex qPCR, which demonstrated the ability to discriminate among $E$. piscicida, E. ictaluri, E. anguillarum, and E. tarda (Reichley et al. 2017).

\section{PHENOTYPIC AND SEROLOGICAL CHARACTERIZATION}

Edwardsiella piscicida is a Gram-negative, oxidase-negative, facultative anaerobe, short and rod-shaped microorganism usually motile. The bacterium is positive for lysine and ornithine decarboxylase, produces $\mathrm{H}_{2} \mathrm{~S}$ and indole from tryptophan, and ferments glucose, mannose and maltose. The phenotypic and physiological properties of E. piscicida 
Table 2. Differential phenotypic characteristics among Edwardsiella species. (+) $90-100 \%$ of strains positive; (-) $0-10 \%$ of strains positive

\begin{tabular}{|lccccc|}
\hline Characteristic & E. tarda & E. hoshinae & E. ictaluri & E. piscicida & E. anguillarum \\
\hline $\mathrm{H}_{2}$ S production & + & $+^{\mathrm{a}}$ & - & + & + \\
Indole production & + & - & - & + & + \\
Voges-Proskauer & - & - & - & - & + \\
Carbon source & & + & - & - & + \\
D-mannitol & - & - & - & - & + \\
L-arabinose & + & + & - & + & - \\
D-mannose & + & + & - & + & - \\
$\beta$-methyl-D-glucoside & + & - & - & - & + \\
L-fucose & + & & & & + \\
L-proline & & & & & + \\
aPositive on Kligler but negative on TSI & & & & \\
\end{tabular}
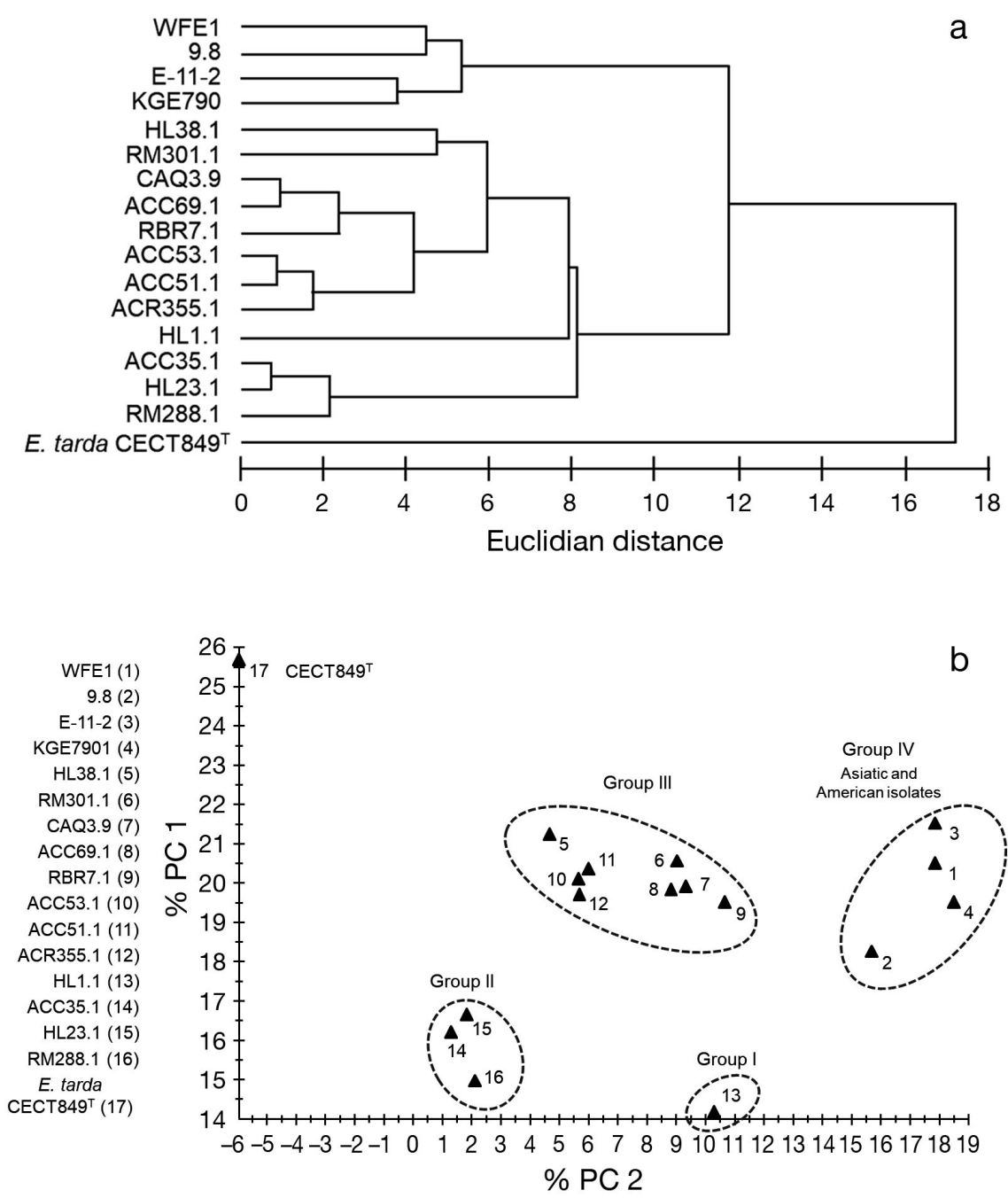

Fig. 1. (a) Dendrogram of Euclidean distance and (b) 2D plot of principal components obtained based on the results of the chromatographic fatty acid profile of different Edwardsiella piscicida isolates. PC1: first principal component; PC2: second principal component assayed during the present study and recovered from other works are listed in Table 3.

The fatty acid profile of this pathogen is composed of 7 principal fatty acids, detected at a level $>1 \%$, including saturated, unsaturated and cyclopropane fatty acids. Among them, the most abundant are the 14:0 (tetradecanoic acid or myristate), 16:0 (hexadecanoic acid or palmitate), 17:0 (analogous of margaric acid), 19:0 $\Delta \omega 8 \mathrm{c}$ (analog of lactobacillic acid) and the summed features SF2 (14:0 3-OH, 16:1 iso I), SF3 $(16: 1 \omega 7 \mathrm{c} / 16: 1 \omega 6 \mathrm{c}, 16: 1 \omega 6 \mathrm{c} /$ $16: 1 \omega 7 \mathrm{c})$ and SF8 $(18: 1 \omega 7 \mathrm{c}, 18: 1 \omega 6 \mathrm{c})$ (Castro 2011, Reichley et al. 2017).

Analyses of the serological relationship among E. piscicida strains, (previously designated as E. tarda), revealed the existence of at least 2 different serotypes, with all serotype 1 isolates stemming from European hosts (Castro et al. 2006, 2012).

\section{GENOTYPING, PHYLOGENY AND CLASSIFICATION}

While E. piscicida and E. tarda are difficult to differentiate by phenotype, there are demonstrable genetic differences between the 2 taxa. Applying randomly amplified polymorphic DNA (RAPD), Castro et al. (2006, 2011c) demonstrated that isolates from turbot 
Table 3. Phenotypic characteristics of Edwardsiella piscicida (Castro et al. 2006, Abayneh et al. 2013, Griffin et al. 2013, Shao et al. 2014, this work). (F) fermentative; (+) 90-100\% of strains positive; (-) $0-10 \%$ of strains positive; (v) $11-89 \%$ of strains positive

\begin{tabular}{|c|c|c|c|}
\hline \multicolumn{2}{|l|}{ Characteristic } & \multicolumn{2}{|l|}{ Carbon source } \\
\hline Motility & $\mathrm{v}$ & D-mannitol & - \\
\hline Oxidase & - & L-arabinose & - \\
\hline Catalase & + & L-rhamnose & - \\
\hline Oxidative/fermentative & $\mathrm{F}$ & Maltose & $\mathrm{v}$ \\
\hline Arginine descarboxilase & - & D-mannose & + \\
\hline Lysine descarboxilase & + & D-galactose & + \\
\hline Ornithine descarboxilase & + & $\beta$-methyl-D-glucoside & - \\
\hline Indole production & + & Tween 80 & $\mathrm{v}$ \\
\hline Voges-Proskauer & - & L-fucose & $\mathrm{v}$ \\
\hline Methyl red & + & Acetic acid & - \\
\hline Simmons' citrate & $\mathrm{V}$ & Citric acid & $\mathrm{v}$ \\
\hline Nitrate reduction & + & Formic acid & - \\
\hline Urease & - & D-glucosaminic acid & $\mathrm{v}$ \\
\hline Aesculin & - & $\alpha$-ketobutyric acid & - \\
\hline Tween 80 & - & $\alpha$-ketovaleric acid & - \\
\hline Amylase & - & Quinic acid & $\mathrm{v}$ \\
\hline $\mathrm{H}_{2} \mathrm{~S}$ production & + & Bromosuccinic acid & $\mathrm{v}$ \\
\hline D-glucose gas production & + & Glucuronamide & + \\
\hline & & L-asparagine & + \\
\hline Growth at & & L-aspartic acid & $\mathrm{v}$ \\
\hline $4^{\circ} \mathrm{C}$ & - & L-glutamic acid & $\mathrm{v}$ \\
\hline $37^{\circ} \mathrm{C}$ & + & L-proline & - \\
\hline $42^{\circ} \mathrm{C}$ & $\mathrm{v}$ & L-serine & + \\
\hline $0 \% \mathrm{NaCl}$ & + & Uridine & $\mathrm{v}$ \\
\hline $3 \% \mathrm{NaCl}$ & + & Glycerol & $\mathrm{v}$ \\
\hline $6 \% \mathrm{NaCl}$ & - & $D, L-\alpha$-glycerol phosphate & $\mathrm{v}$ \\
\hline
\end{tabular}

and sole, previously identified as E. tarda but now reclassified as E. piscicida, comprised a unique group with a different fingerprint from those obtained for bona fide E. tarda strains. Moreover, 2 different E. piscicida clonal lineages coexisting in a single farm but from different outbreaks where identified by RAPD. Repetitive sequence mediated PCR has also been shown to differentiate between different E. piscicida strains (Castro et al. 2011c, Griffin et al. 2013, Camus et al. 2016, Shafiei et al. 2016, Reichley et al. 2017). REP-PCR was used to detect different clonal lineages in a single farm even within the same outbreak (Castro et al. 2011c). In contrast, enterobacterial repetitive intergenic consensus PCR (ERIC-PCR) and BOX-PCR demonstrated a high degree of genetic homogeneity among E. piscicida isolates tested, although both techniques generated distinct banding patterns for each species of the genus (Griffin et al. 2014, Reichley et al. 2017). Due to the relative similarity among isolates from different hosts and geographic origins, the lack of resolution provided by ERIC-PCR renders it unsuitable for epidemiological analysis of edwardsiellosis (Shafiei et al. 2016). Genotyping of E. piscicida using amplified fragment length polymorphism (AFLP) also separates this species into an independent cluster from other members of the Edwardsiella genus, adding to the techniques that may be useful for classification (Buján et al. 2018b). Plasmid profiling of different E. piscicida isolates carried out by Reichley et al. (2017) found variability in size, composition and arrangement among the plasmids studied. However, it is noteworthy that the plasmids of turbot isolates used in this study were identical, implying an epidemiological link or host-adaptive factors associated with the plasmids (Reichley et al. 2017).

The recognition of $E$. piscicida and $E$. anguillarum as species required a revision of Edwardsiella systematics. The tool most used for classification and identification is the sequencing of 16S rRNA. For Edwardsiella, phylogenetic analysis based on the 16S rRNA gene has demonstrated low resolving power (Fig. 2), which, coupled with arbitrary similarity cutoffs and misidentification within public nucleotide databases, has led to erroneous identifications due to the high degree of $16 \mathrm{~S}$ rRNA variability within the genus (Shao et al. 2015, Reichley et al. 2017, Buján et al. 2018b). In comparison, the genes sodB and gyrB, and dnaJ employed by Reichley et al. (2017) and Buján et al. (2018b) respectively have higher discriminatory power.

Multilocus sequence analysis (MLSA) has grouped E. piscicida strains in a robust clade separate from the other members of the genus (Fig. 3) (Abayneh et al. 2012, Griffin et al. 2013, Buján et al. 2018b), suggesting that MLSA is an adequate tool to determine inter- and intra-specific variability within the $E d$ wardsiella genus. Furthermore, similar methods indicate genetic discontinuity within E. piscicida, reflected by a high number of unique sequence types (Yang et al. 2013). It is interesting to note that all E. piscicida isolates from Asian countries are compiled in 2 clonal complexes, while all isolates from European turbot and sole comprise a single separate sequence type (Buján et al. 2018a). This may reflect genetic changes associated with adaption to a new environment through geographical isolation and/or infection of different hosts. 
Multilocus variable-number tandem repeat analysis (MLVA) has also been employed successfully with sufficient resolving power for epidemiological and phylogenetic analysis of E. piscicida isolates pathogenic to fish (Abayneh et al. 2014).

Advances in complete genome sequencing resulted in the availability of several E. piscicida (Oguro et al. 2014, Reichley et al. 2016, Buján et al. 2018b) and E. tarda genomes (Reichley et al. 2015a, Buján et al. 2018a). The comparative studies of these and other whole genomes of the genus Edwardsiella shows that complete genome sequencing is the most reliable taxonomic tool (Buján et al. 2018b).

Fig. 2. Phylogenetic tree based on partial 16S rRNA gene sequences constructed by the ML algorithm (TN93+G). Serratia rubidaea CIP $103234^{\mathrm{T}}$ was used as outgroup. Bootstrap ( $\geq 60 \%$ ) from 1000 replications appears next to corresponding branch. Scale bar: 0.005 substitutions per nucleotide position. Based on Buján et al. (2018b)

\section{PATHOGENESIS AND VIRULENCE MECHANISMS}

Experimental infection studies have demonstrated that E. piscicida is highly pathogenic, not only for the host from which it was isolated but also for other fish species such as zebrafish (Castro et al. 2011a, Abayneh et al. 2012). Therefore, E. piscicida does not seem to exhibit host specificity, and edwardsiellosis may be a risk for many marine fish species.

The clinical signs of $E$. piscicida infection are common to all species of fish suffering from the disease.

E. piscicida EDK1

E. piscicida NCIMB $14824^{\top}$

E. piscicida EIB202

E. piscicida FL6-60

E. piscicida C07-087

E. piscicida ET006

E. piscicida ET001

E. piscicida WFE10

E. piscicida WFE1

E. piscicida FL4-53-4K

E. piscicida $\mathrm{E}-11-2$

E. piscicida 07BS

E. piscicida KGE7901

E. piscicida $\mathrm{V} 12$

E. piscicida ACR419.1

E. piscicida $\mathrm{CH} 1.1$

E. piscicida $\mathrm{Fr} 1372$

E. piscicida CAQ6.1

E. piscicida ACR355.1

E. piscicida RBR7.1

E. piscicida RM288.1

E. piscicida ACC35.1

E. piscicida $\mathrm{HL} 1.1$

E. piscicida 9.8

E. anguillarum ET009
E. anguillarum $205-03$
E. anguillarum DSM $27202^{\top}$
E. ictaluri CECT $885^{\top}$
E. hoshinae DSMZ $13771^{\top}$
E. tarda NCIMB 2034
E. tarda CECT $849^{\top}$

Serratia rubidaea NBRC $103169^{\top}$ 


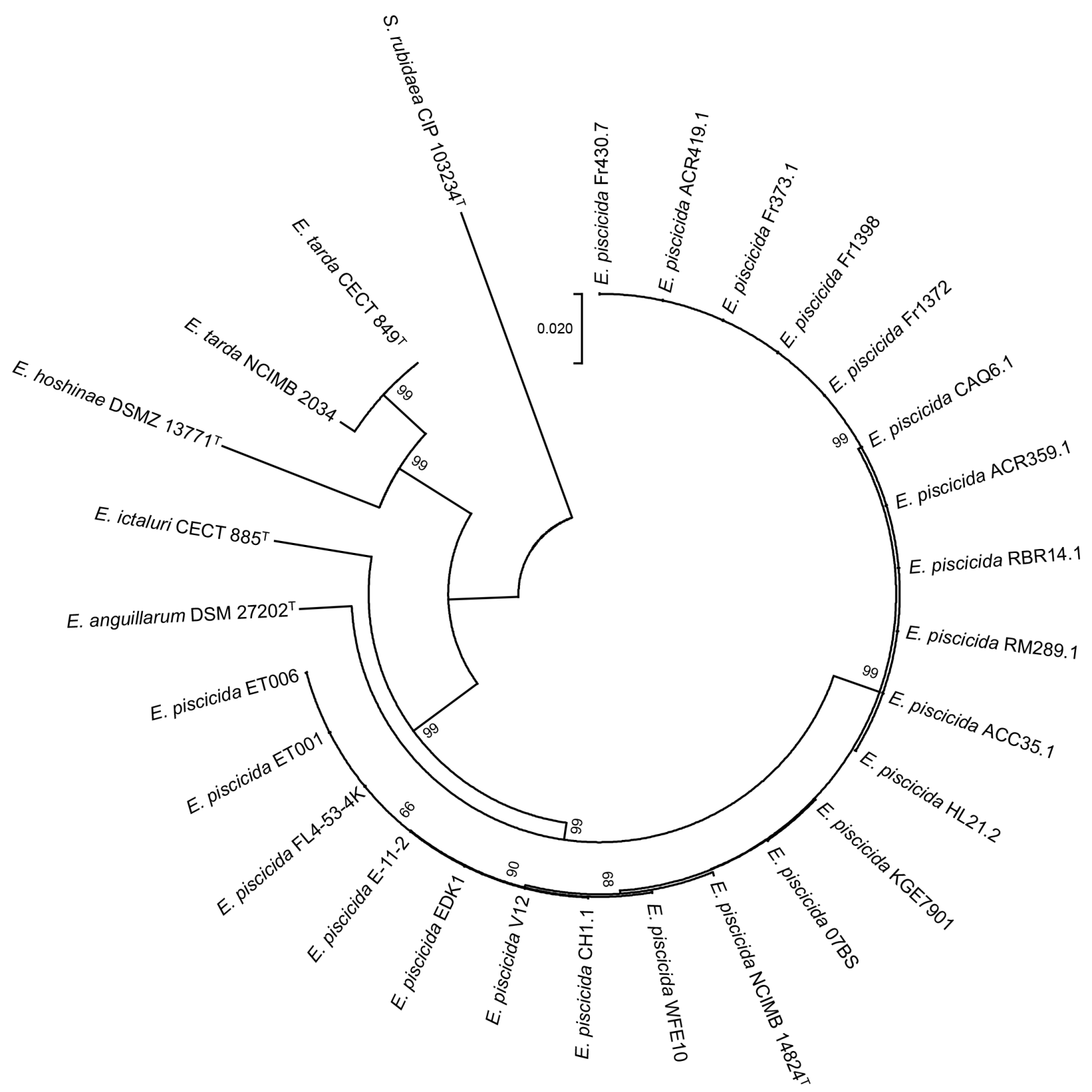

Fig. 3. Phylogenetic tree based on the concatenation of the nucleotide sequences of 6 housekeeping genes (adk, atpD, dnaJ, glnA, hsp60, tuf) by the NJ method (Kimura 2-parameter model). Serratia rubidaea CIP $103234^{\mathrm{T}}$ was used as outgroup. Bootstrap ( $\geq 60 \%$ ) from 1000 replications appears next to corresponding branch. Scale bar: 0.02 substitutions per nucleotide position. Based on Buján et al. (2018b)

Externally, affected fish show discolored areas of the skin with loss of pigmentation, external haemorrhages and a general septicemia in the ventral muscle (Shetty et al. 2014, Griffin et al. 2017). Moreover, exophthalmia, abundant ascitic fluid and general petechiae in the internal organs were also observed in turbot Scophthalmus maximus (Castro et al. 2006), and abscesses and nodules in the visceral organs in sharp snout seabream Diplodus puntazzo were also described (Katharios et al. 2015). Histological examinations performed in largemouth bass revealed multifocal necrosis scattered throughout the heart, liver, anterior kidney, posterior kidney and spleen (Fogelson et al. 2016).

Several potential virulence factors implicated in the infection process of E. piscicida have been proposed. Extracellular products include chondroitinase, related to cartilage degradation (Waltman et al. 
1986, Shotts \& Cooper 1992), with homologues recently reported in European turbot isolates of E. piscicida (Castro et al. 2016) and in an Asian turbot strain of this species (Yang et al. 2012). Different hemolysins and their precursors (EthA, EthB and SlyA) have also been detected (Janda et al. 1991, Kumar et al. 2010, Wang et al. 2010, Xiao et al. 2012).

Contact and adherence to the host often comprise early stages of infection. The invasin Inv1 has been identified in E. piscicida (Li et al. 2012), and E. piscicida presents different adhesins on the cell surface including flagellins (FliC, FlgD) (Park et al. 2011, He et al. 2012, Liu et al. 2012, Buján et al. 2015a, X. Liu et al. 2017b), fimbrial proteins (FimA) (Srinivasa Rao et al. 2003, Kim et al. 2014) and other adhesins (AIDA) (Sakai et al. 2009). FliC, along with sigma factor RpoS may be involved in the development of biofilms (Xiao et al. 2009, He et al. 2012), although Shafiei et al. (2016) reported the inability of highly virulent $E$. piscicida to form thick biofilms under the conditions tested. Moreover, comparative proteomics of strains with a different degree of virulence implicate flagellin (FliC) in virulence. Indeed, recent unpublished work in our laboratory indicate that flagella-impaired mutants (via flgG) are attenuated in turbot and increase biofilm formation (N. Castro unpubl. data).

To survive and subsequently multiply, the microorganisms have a series of mechanisms to resist their host's defenses. Under stress conditions, such as serum resistance or replication in macrophages, E. piscicida expresses proteins of the catalase family (KatB and KatG) (Han et al. 2006, Xiao et al. 2012), heat shock proteins (HtpG and Hsp60) (Dang et al. 2011), superoxide dismutase (SodB and SodC) (Han et al. 2006, Gao et al. 2016) and 2-component systems (EsrA-EsrB) (Liu Y et al. 2017, Yin et al. 2017). E. piscicida produces the hydroxamate-type siderophore vibrioferrin and can utilize heme groups (hemin or haemoglobin) as an iron source by direct binding (Castro et al. 2016). Under iron limitation this iron uptake system is upregulated along with hemolysin, hydrolases and stress protein Hsp90. Proteins involved in transport, carbohydrate metabolism and amino acid synthesis were also up-regulated (Buján et al. 2015b).

Secretion systems are used by a multitude of microorganisms to release different virulence factors (quorum sensing regulators, exotoxins and exoenzymes) within the host (Tan et al. 2005, Leung et al. 2012). In E. piscicida, the proteins EseB, EseC, EseD and EseH belonging to the type III secretion system, are related to the translocation of effector proteins in infected host cells (Srinivasa Rao et al. 2004, Hou et al. 2017). Moreover, proteins of the type VI secretion system, EvpA, EvpB and EvpC (Edwardsiella virulence protein) are associated with virulence of E. piscicida (Tan et al. 2005, Chakraborty et al. 2011) although the details of their functions are still unknown (Srinivasa Rao et al. 2004). With regard to quorum sensing systems, Romero et al. (2014) reported in vitro detection of the $\mathrm{N}$-acyl homoserine lactones (AHLs) C6-HSL and OC6-HSL and Castro et al. (2016) showed the production of these molecules in vivo during fish infections. Moreover, they demonstrated a strong increase in AHL production when the fish were infected with low doses of bacteria consistent with AHL production in E. piscicida being under density-dependent control in the fish. Castro et al. (2016) also described the presence of genes involved in AHL production (AI1), the AI2 system (luxS) and the QscBC system.

\section{TREATMENT AND PREVENTION}

In vitro antimicrobial susceptibility testing of $E$. piscicida indicates that, to date, strains isolated from different hosts and geographical regions are susceptible to most commonly used antibiotics for the treatment of edwardsiellosis, including enrofloxacin, oxytetracycline, trimethoprim/sulfamethoxazole or florfenicol among others (Castro et al. 2006, Shafiei et al. 2016, Reichley et al. 2017, Kim et al. 2018).

Prophylactic vaccines are the most cost-effective tools for preventing bacterial infections. Kwon et al. (2006), Castro et al. (2008) and Sun et al. (2011) evaluated the effectiveness of different formalin-killed formulations in turbot, tilapia and flounder respectively. These were found to be generally effective, with the adjuvanted vaccine developed by Castro et al. (2008) providing highest protection. Several live attenuated vaccines were tested in turbot and zebrafish with high relative percent survival (RPS) values (Xiao et al. 2011, 2013, Wang et al. 2013, Yan et al. 2013, Yang et al. 2015) but they are not appropriate for commercial applications due to biosafety and environmental risks. In E. piscicida different recombinant proteins were evaluated as potential protective antigens. F. Liu et al. (2016b, 2017) developed various vaccines based on the membrane proteins rOmpI, rOmpX and OmpC obtaining high RPS values (over $80 \%$ ) in flounder. Flagellar proteins were tested by Zhang et al. (2012) in zebrafish and by $X$. Liu et al. (2017b) in turbot obtaining the best RPS values with the protein FlgD $(76 \%$ and $70 \%$ res- 
pectively). The effectiveness of the FlgD protein as vaccine was supported by X. Liu et al. (2017a), in zebrafish and turbot, using reverse vaccinology approach. On the other hand, the GroEL DNA vaccine tested by Liu et al. (2016a) and the chimeric DNA vaccine encoding the flagellar genes Eta6 fused in-frame to FliC developed by Jiao et al. (2009), were protective in flounder with RPS values of $60 \%$ and $72 \%$, respectively. However, better results (RPS over $87 \%$ ) were obtained in flounder by a bicistronic vaccination using the flgD gene, adjuvanted with C5a peptidase protein driven by a modified cytomegalovirus promoter/enhancer to increase gene expression (Liu et al. 2016b). Polyvalent vaccines obtained by shuffling 6 ompA genes of 4 bacteria, $V$. alginolyticus, V. parahaemolyticus, E. piscicida and E. coli, were effective in zebrafish assays with values of RPS over $80 \%$ (Cheng et al. 2018).

\section{CONCLUDING REMARKS}

In this work, we review the current literature on fish edwardsiellosis caused by E. piscicida. Much recent effort has focused on correct identification, classification and phylogenetic positioning of this fish pathogen. As we have seen before, the difficulty in validating and reproducing phenotypic tests to identify species of the Edwardsiella genus correctly has necessitated use of specific PCR (Griffin et al. 2014) or sequencing of genes such as dnaJ (Buján et al. 2018b) or gyrB (Griffin et al. 2014) for accurate differential identification. Virulence mechanisms seem to be largely aligned with other enteric fish pathogens. However, further information on the epidemiology, strain variation and host-pathogen interactions of this species are required to prevent economic losses in the aquaculture industry through biosecurity other preventative measures. Moreover, whether E. piscicida is exclusively a fish pathogen or has zoonotic role, as in the case of $E$. tarda, needs to be elucidated.

Acknowledgements. The study was supported by Ministerio de Economía y Competitividad, Spain (AGL2012-31049), and Xunta de Galicia, Spain (GRC-2014/007).

\section{LITERATURE CITED}

Abayneh T, Colquhoun DJ, Sørum H (2012) Multi-locus sequence analysis (MLSA) of Edwardsiella tarda isolates from fish. Vet Microbiol 158:367-375

Abayneh T, Colquhoun DJ, Sørum H (2013) Edwardsiella piscicida sp. nov., a novel species pathogenic to fish. J Appl Microbiol 114:644-654
Abayneh T, Colquhoun DJ, Austin D, Sørum H (2014) Multilocus variable number tandem repeat analysis of Edwardsiella piscicida isolates pathogenic to fish. J Fish Dis 37:941-948

Bai FF, Lan JX, Wang Y, Han Y, Zhang XH (2009) Indirect enzyme-linked immunosorbent assay (ELISA) for rapid detection of Edwardsiella tarda. J Fish Sci Chin 16: 619-625

Barja JL, Castro N, Guitián E, Toranzo AE, Magariños B (2008) Utilidad del MALDI-TOF para la identificacióncaracterización de bacterias acuáticas. In: Iriberri J, Ayo B (eds) VII reunión científica de microbiología del medio acuático. Universidad del País Vasco-Euskal Herriko Unibertsitatea UPV-EHU, Bilbao, p 92

*Baya AM, Romalde JL, Green DE, Navarro RB, Evans J, May EB, Toranzo AE (1997) Edwardsiellosis in wild striped bass from the Chesapeake Bay. J Wildl Dis 33: 517-525

Brenner DJ (1978) Characterization and clinical identification of Enterobacteriaceae by DNA hybridation. Prog Clin Pathol 7:71-117

Brenner DJ (1984) Family Enterobacteriaceae. In: Krieg NR, Holt JC (eds) Bergey's manual of systematic bacteriology. Williams \& Wilkins, Baltimore, MD, p 408-516

*Buján N, Hernández-Haro C, Monteoliva L, Gil C, Magariños B (2015a) Comparative proteomic study of Edwardsiella tarda strains with different degrees of virulence. J Proteomics 127:310-320

Buján N, Reales-Calderón JA, Monteoliva L, Gil C, Magariños B (2015b) Caracterización del proteoma de Edwardsiella tarda cultivada en diferentes condiciones de disponibilidad de hierro. In: González-Fandos E (ed) Avances en Micorbiología. XXV congreso bacional de microbiología. Universidad de la Rioja, Logroño, p 144

* Buján N, Toranzo AE, Magariños B (2017) Draft genome sequence of Edwardsiella piscicida strain ACC35.1 isolated from diseased turbot (Scophthalmus maximus) in Europe. Genome Announc 5:e01626-16

* Buján N, Mohammed H, Balboa S, Romalde JL, Toranzo AE, Arias CR, Magariños B (2018a) Genetic studies to reaffiliate Edwardsiella tarda fish isolates to Edwardsiella piscicida and Edwardsiella anguillarum species. Syst Appl Microbiol 41:30-37

* Buján N, Balboa S, Romalde JL, Toranzo AE, Magariños B (2018b) Population genetic and evolution analysis of controversial genus Edwardsiella by multilocus sequence typing. Mol Phylogenet Evol 127:513-521

Camus A, Dill J, McDermott A, Hatcher N, Griffin M (2016) Edwardsiella piscicida-associated septicaemia in a blotched fantail stingray Taeniura meyeni (Müeller \& Henle). J Fish Dis 39:1125-1131

Castro N (2011) Edwardsiella tarda: patógeno emergente en el cultivo del rodaballo. $\mathrm{PhD}$ dissertation, Universidad de Santiago de Compostela

* Castro N, Toranzo AE, Barja JL, Núñez S, Magariños B (2006) Characterization of Edwardsiella tarda strains isolated from turbot. J Fish Dis 29:541-547

* Castro N, Toranzo AE, Núñez S, Magariños B (2008) Development of an effective Edwardsiella tarda vaccine for cultured turbot (Scophthalmus maximus). Fish Shellfish Immunol 25:208-212

Castro N, Magariños B, Núñez S, Barja JL, Toranzo AE (2011a) Pathogenic potential of Edwardsiella tarda strains isolated from turbot. Fish Pathol 46:27-30

Castro N, Toranzo AE, Nuñez S, Magariños B (2011b) Eval- 
uation of the selective and differential ET medium for detection of Edwardsiella tarda in aquaculture systems. Lett Appl Microbiol 53:114-119

Castro N, Toranzo AE, Bastardo A, Barja JL, Magariños B (2011c) Intraspecific genetic variability of Edwardsiella tarda strains from cultured turbot. Dis Aquat Org 95: 253-258

* Castro N, Toranzo AE, Devesa S, González A, Nuñez S, Magariños B (2012) First description of Edwardsiella tarda in Senegalese sole, Solea senegalensis (Kaup). J Fish Dis 35:79-82

Castro N, Osorio CR, Buján N, Fuentes JC and others (2016) Insights into the virulence-related genes of Edwardsiella tarda isolated from turbot in Europe: genetic homogeneity and evidence for vibrioferrin production. J Fish Dis 39:565-576

* Chakraborty S, Sivaraman J, Leung KY, Mok YK (2011) Two-component PhoB-PhoR regulatory system and ferric uptake regulator sense phosphate and iron to control virulence genes in type III and VI secretion systems of Edwardsiella tarda. J Biol Chem 286:39417-39430

Chen J, Lai S (1998) PCR for direct detection of Edwardsiella tarda from infected fish and environmental water by application of the hemolysin gene. Zool Stud 37:169-176

Cheng ZX, Chu X, Wang SN, Peng XX, Li H (2018) Six genes of ompA family shuffling for development of polyvalent vaccines against Vibrio alginolyticus and Edwardsiella tarda. Fish Shellfish Immunol 75:308-315

Dang W, Hu YH, Sun L (2011) HtpG is involved in the pathogenesis of Edwardsiella tarda. Vet Microbiol 152:394-400

'Du M, Chen J, Zhang X, Li A, Li Y, Wang Y (2007) Retention of virulence in a viable but nonculturable Edwardsiella tarda isolate. Appl Environ Microbiol 73:1349-1354

Ewing WH, Mcwhorter AC, Escobar MR, Lubin AH (1965) Edwardsiella, a new genus of Enterobacteriaceae based on a new species, E. tarda. Int Bull Bacteriol Nomencl Taxon 15:33-38

Farmer JJ III, Brenner DJ, Clark WA (1976) Proposal to conserve the specific epithet tarda over the specific epithet anguillimortiferum in the name of the organism presently known as Edwardsiella tarda: request for an Opinion. Int J Syst Bacteriol 26:293-294

Fogelson SB, Petty BD, Reichley SR, Ware C and others (2016) Histologic and molecular characterization of Edwardsiella piscicida infection in largemouth bass (Micropterus salmoides). J Vet Diagn Invest 28:338-344

Gao D, Li Y, Zheng E, Liu N, Shao Z, Lu C (2016) Eha, a regulator of Edwardsiella tarda, required for resistance to oxidative stress in macrophages. FEMS Microbiol Lett 363:fnw192

Griffin MJ, Quiniou SM, Cody T, Tabuchi M and others (2013) Comparative analysis of Edwardsiella isolates from fish in the eastern United States identifies two distinct genetic taxa amongst organisms phenotypically classified as E. tarda. Vet Microbiol 165:358-372

* Griffin MJ, Ware C, Quiniou SM, Steadman JM, Gaunt PS, Khoo LH, Soto E (2014) Edwardsiella piscicida identified in the southeastern USA by gyrB sequence, speciesspecific and repetitive sequence-mediated PCR. Dis Aquat Org 108:23-35

Griffin MJ, Greenway TE, Wise DJ (2017) Edwardsiella spp. In: Woo PTK, Cipriano RC (eds) Fish viruses and bacteria: pathobiology and protection. $\mathrm{CAB}$ International, Boston, MA, p 190-210

* Grimont PAD, Grimont F, Richard C, Sakazaki R (1980)
Edwardsiella hoshinae, a new species of Enterobacteriaceae. Curr Microbiol 4:347-351

*Han HJ, Kim DH, Lee DC, Kim SM, Park SI (2006) Pathogenicity of Edwardsiella tarda to olive flounder, Paralichthys olivaceus (Temminck \& Schlegel). J Fish Dis 29: 601-609

* Hawke JP, McWhorter AC, Steigerwalt AG, Brenner DJ (1981) Edwardsiella ictaluri sp. nov., the causative agent of enteric septicemia of catfish. Int J Syst Evol Microbiol 31:396-400

$\mathrm{He}$ Y, Xu T, Fossheim LE, Zhang XH (2012) FliC, a flagellin, is a essential for the growth and virulence of fish pathogen Edwardsiella tarda. PLOS ONE 7:e45070

*Hou M, Chen R, Yang D, Núñez G and others (2017) Identification and functional characterization of $\mathrm{EseH}$, a new effector of the type III secretion system of Edwardsiella piscicida. Cell Microbiol 19:e12638

Janda JM, Abbott SL, Kroske-Bystrom S, Cheung WK, Powers C, Kokka RP, Tamura K (1991) Pathogenic properties of Edwardsiella species. J Clin Microbiol 29:1997-2001

Jiao XD, Zhang M, Hu YH, Sun L (2009) Construction and evaluation of DNA vaccines encoding Edwardsiella tarda antigens. Vaccine 27:5195-5202

Katharios P, Kokkari C, Dourala N, Smyrli M (2015) First report of edwardsiellosis in cage-cultured sharpsnout sea bream, Diplodus puntazzo from the Mediterranean. BMC Vet Res 11:155

Kim KI, Kang JY, Park JY, Joh SJ, Lee HS, Kwon YK (2014) Phenotypic traits, virulence-associated gene profile and genetic relatedness of Edwardsiella tarda isolates from Japanese eel Anguilla japonica in Korea. Lett Appl Microbiol 58:168-176

Kim A, Lim Y, Kim N, Luan Nguyen T and others (2018) A comparison of genotypic and phenotypic methods for analyzing the susceptibility to sulfamethoxazole and trimethoprim in Edwardsiella piscicida. Microb Drug Resist (in press). doi:10.1089/mdr.2017.0137

KKing MB, Adler DL (1964) A previously undescribed group of Enterobacteriaceae. Am J Clin Pathol 41:230

* Kumar G, Sharma P, Rathore G, Bisht D, Sengupta U (2010) Proteomic analysis of outer membrane proteins of $E d$ wardsiella tarda. J Appl Microbiol 108:2214-2221

Kwon SR, Nam YK, Kim SK, Kim KH (2006) Protection of tilapia (Oreochromis mosambicus) from edwardsiellosis by vaccination with Edwardsiella tarda ghosts. Fish Shellfish Immunol 20:621-626

K Lan J, Zhang XH, Wang Y, Chen J, Han Y (2008) Isolation of an unusual strain of Edwardsiella tarda from turbot and establish a PCR detection technique with the gyrB gene. J Appl Microbiol 105:644-651

ㄴoung KY, Siame BA, Tenkink BJ, Noort RJ, Mok YK (2012) Edwardsiella tarda - virulence mechanisms of an emerging gastroenteritis pathogen. Microbes Infect 14:26-34

Li H, Zhu QF, Peng XX, Peng B (2017) Interactome of E. piscicida and grouper liver proteins reveals strategies of bacterial infection and host immune response. Sci Rep 7: 39824

Li MF, Hu YH, Zheng WJ, Sun BG, Wang CL, Sun L (2012) Inv1: an Edwardsiella tarda invasin and a protective immunogen that is required for host infection. Fish Shellfish Immunol 32:586-592

Lindquist JA (1991) Medium and procedure for the direct, selective isolation of Edwardsiella tarda from environmental water samples. Abstr Annu Meet Am Soc Microbiol C-303:302 
Ling SHM, Wang XH, Xie L, Lim TM, Leung KY (2000) Use of green fluorescent protein (GFP) to study the invasion pathways of Edwardsiella tarda in in vivo and in vitro fish models. Microbiology 146:7-19

Liu F, Tang X, Sheng X, Xing J, Zhan W (2016a) DNA vaccine encoding molecular chaperone GroEL of Edwardsiella tarda confers protective efficacy against edwardsiellosis. Mol Immunol 79:55-65

*iu F, Tang X, Sheng X, Xing J, Zhan W (2016b) Edwardsiella tarda outer membrane protein $\mathrm{C}$ : an immunogenic protein induces highly protective effects in flounder (Paralichthys olivaceus) against edwardsiellosis. Int J Mol Sci $17: 1117$

*iu F, Tang X, Sheng X, Xing J, Zhan W (2017) Comparative study of the vaccine potential of six outer membrane proteins of Edwardsiella tarda and the immune responses of flounder (Paralichthys olivaceus) after vaccination. Vet Immunol Immunopathol 185:38-47

Liu Y, Zhang H, Liu Y, Li H, Peng X (2012) Determination of the heterogeneous interactome between Edwardsiella tarda and fish gills. J Proteomics 75:1119-1128

Liu X, Sun J, Wu H (2017a) Glycolysis-related proteins are broad spectrum vaccine candidates against aquacultural pathogens. Vaccine 35:3813-3816

Liu X, Zhang H, Jiao C, Liu Q, Zhang Y, Xiao J (2017b) Flagellin enhances the immunoprotection of formalininactivated Edwardsiella tarda vaccine in turbot. Vaccine 35:369-374

Liu Y, Zhao L, Yang M, Yin K and others (2017) Transcriptomic dissection of the horizontally acquired response regulator EsrB reveals its global regulatory roles in the physiological adaptation and activation of T3SS and the cognate effector repertoire in Edwardsiella piscicida during infection toward turbot. Virulence 8:1355-1377

* Loch PT, Hawke JP, Reichley SR, Faisal M, Del Piero F, Griffin MJ (2017) Outbreaks of edwardsiellosis caused by Edwardsiella piscicida and Edwardsiella tarda in farmed barramundi (Lates calcarifer). Aquaculture 481:202-210

Mäkelä PH, Mayer H (1976) Enterobacterial common antigen. Bacteriol Rev 40:591-632

Matsuyama T, Kamaishi T, Ooseko N, Kurohara K, Iida T (2005) Pathogenicity of motile and non-motile Edwardsiella tarda to some marine fish. Fish Pathol 40:133-135

Nakatsugawa T (1983) Edwardsiella tarda isolated from cultured young flounders. Fish Pathol 18:99-101

* Oguro K, Tamura K, Yamane J, Shimizu M and others (2014) Draft genome sequences of two genetic variant strains of Edwardsiella piscicida, JF1305 and RSB1309, isolated from olive flounder (Paralichythys olivaceus) and red sea bream (Pagrus major) cultured in Japan, respectively. Genome Announc 2:e00546-14

Park SB, Jang HB, Nho SW, Cha IS and others (2011) Outer membrane vesicles as a candidate vaccine against edwardsiellosis. PLOS ONE 6:e17629

* Reichley SR, Waldbieser GC, Tekedar HC, Lawrence ML, Griffin MJ (2015a) Complete genome sequence of Edwardsiella tarda isolate FL95-01, recovered from channel catfish. Genome Announc 3:e00682-15

Reichley SR, Ware C, Greenway TE, Wise DJ, Griffin MJ (2015b) Real-time polymerase chain reaction assays for the detection and quantification of Edwardsiella tarda, Edwardsiella piscicida, and Edwardsiella piscicida-like species in catfish tissues and pond water. J Vet Diagn Invest 27:130-139

Reichley SR, Waldbieser GC, Tekedar HC, Lawrence ML,
Griffin MJ (2016) Complete genome sequence of Edwardsiella piscicida isolate S11-285 recovered from channel catfish (Ictalurus punctatus) in Mississippi, USA. Genome Announc 4:e01259-16

Reichley SR, Ware C, Steadman J, Gaunt PS and others (2017) Comparative phenotypic and genotypic analysis of Edwardsiella spp. isolates from different hosts and geographic origins, with an emphasis on isolates formerly classified as E. tarda and an evaluation of diagnostic methods. J Clin Microbiol 55:3466-3491

Romero M, Muras A, Mayer C, Buján N, Magariños B, Otero A (2014) In vitro quenching of fish pathogen Edwardsiella tarda AHL production using marine bacterium Tenacibaculum sp. strain 20J cell extracts. Dis Aquat Org 108:217-225

Sakai T, Iida T, Osatomi K, Kanai K (2007) Detection of type 1 fimbrial genes in fish pathogenic and non-pathogenic Edwardsiella tarda strains by PCR. Fish Pathol 42: 115-117

* Sakai T, Matsuyama T, Nishioka T, Nakayasu C, Kamaishi $\mathrm{T}$, Yamaguchi K, Iida T (2009) Identification of major antigenic proteins of Edwardsiella tarda recognized by Japanese flounder antibody. J Vet Diagn Invest 21: 504-509

Sakazaki R, Murata Y (1962) The new group of the Enterobacteriaceae, the Asakusa group. Jpn J Bacteriol 17: 616-617 (in Japanese)

Sakazaki R, Tamura K (1975) Priority of the specific epithet anguillimortiferum over the specific epithet tarda in the name of the organism presently known as Edwardsiella tarda. Int J Syst Evol Microbiol 25:219-220

* Shafiei S, Viljamaa-Dirks S, Sundell K, Heinikainen S, Abayneh T, Wiklund T (2016) Recovery of Edwardsiella piscicida from farmed white-fish, Coregonus lavaretus (L.), in Finland. Aquaculture 454:19-26

* Shao S, Lai Q, Liu Q, Wu H and others (2015) Phylogenomics characterization of a highly virulent Edwardsiella strain ET080813 ${ }^{\mathrm{T}}$ encoding two distinct T3SS and three T6SS gene clusters: propose a novel species as Edwardsiella anguillarum sp. nov. Syst Appl Microbiol 38:36-47

* Shetty M, Maiti B, Venugopal MN, Karunasagar I (2014) First isolation and characterization of Edwardsiella tarda from diseased striped catfish, Pangasianodon hypophthalmus (Sauvage). J Fish Dis 37:265-271

Shotts EB, Cooper RK (1992) Chondroitinase attenuated Edwardsiella ictaluri and a vaccine for prevention of enteric septicemia (ES) in fish. United States Patent 5536658

Srinivasa Rao PS, Lim TM, Leung KY (2003) Functional genomics approach to the identification of virulence genes involved in Edwardsiella tarda pathogenesis. Infect Immun 71:1343-1351

* Srinivasa Rao PS, Yamada Y, Peng Tan Y, Leung KY (2004) Use of proteomics to identify novel virulence determinants that are required for Edwardsiella tarda pathogenesis. Mol Microbiol 53:573-586

Sun Y, Liu CS, Sun L (2011) A multivalent killed whole-cell vaccine induces effective protection against Edwardsiella tarda and Vibrio anguillarum. Fish Shellfish Immunol 31:595-599

* Takano T, Matsuyama T, Oseko N, Sakai T and others (2010) The efficacy of five avirulent Edwardsiella tarda strains in a live vaccine against edwardsiellosis in Japanese flounder, Paralichthys olivaceus. Fish Shellfish Immunol 29:687-693 
Tan YP, Zheng J, Tung SL, Rosenshine I, Leung KY (2005) Role of type III secretion in Edwardsiella tarda virulence. Microbiology 151:2301-2313

Tekedar HC, Karsi A, Williams ML, Vamenta S and others (2013) Complete genome sequence of channel catfish gastrointestinal septicemia isolate Edwardsiella tarda C07-087. Genome Announc 1:e00959-13

van Soest JJ, Stockhammer OW, Ordas A, Bloemberg GV, Spaink HP, Meijer AH (2011) Comparison of static immersion and intravenous injection systems for exposure of zebrafish embryos to the natural pathogen Edwardsiella tarda. BMC Immunol 12:58

Waltman WD, Shotts EB, Hsu TC (1986) Biochemical characteristics of Edwardsiella ictaluri. Appl Environ Microbiol 51:101-104

Wang B, Sun C, Fan W, Liu SF, Liu YB, Sun YK (2006) Pathogenicity and identification of pathogenic bacterium causing hemorrhagic septicemia in cultured turbot (Scophthalmus maximus). J Dalian Fish Univ 21:100-104

Wang X, Wang Q, Xiao J, Liu Q, Wu H, Zhang Y (2010) Hemolysin EthA in Edwardsiella tarda is essential for fish invasion in vivo and in vitro and regulated by twocomponent system EsrA-EsrB and nucleoid protein Hha $_{\mathrm{Et}}$. Fish Shellfish Immunol 29:1082-1091

Wang YM, Wang QY, Xiao JF, Liu Q, Wu HZ, Zhang YX (2011) Genetic relationships of Edwardsiella strains isolated in China aquaculture revealed by rep-PCR genomic fingerprinting and investigation of Edwardsiella virulence genes. J Appl Microbiol 111:1337-1348

Wang Y, Wang Q, Yang W, Liu B, Zhang Y (2013) Functional characterization of Edwardsiella tarda twin-arginine translocation system and its potential use as biological containment in live attenuated vaccine of marine fish. Appl Microbiol Biotechnol 97:3545-3557

Xiao J, Wang Q, Liu Q, Wang X, Liu H, Zhang Y (2008) Isolation and identification of fish pathogen Edwardsiella tarda from mariculture in China. Aquacult Res 40:13-17

Xiao J, Wang Q, Liu Q, Xu L, Wang X, Wu H, Zhang Y (2009) Characterization of Edwardsiella tarda rpoS: effect on serum resistance, chondroitinase activity, biofilm formation, and autoinducer synthetases expression. Appl Microbiol Biotechnol 83:151-160

Xiao J, Chen T, Wang Q, Liu Q and others (2011) Search for live attenuated vaccine candidate against edwardsiellosis by mutating virulence-related genes of fish

Editorial responsibility: Andrew Barnes,

Brisbane, Queensland, Australia pathogen Edwardsiella tarda. Lett Appl Microbiol 53: 430-437

Xiao J, Chen T, Wang Q, Zhang Y (2012) Comparative analysis of the roles of catalases KatB and KatG in the physiological fitness and pathogenesis of fish pathogen Edwardsiella tarda. Lett Appl Microbiol 54:425-432

*Xiao J, Chen T, Liu B, Yang W, Wang Q, Qu J, Zhang Y (2013) Edwardsiella tarda mutant disrupted in type III secretion system and chorismic acid synthesis and cured of a plasmid as a live attenuated vaccine in turbot. Fish Shellfish Immunol 35:632-641

*Yamada Y, Wakabayashi H (1999) Identification of fish pathogenic strains belonging to genus Edwardsiella by sequence analysis of sodB. Fish Pathol 34:145-150

* Yan Y, Mu W, Zhang L, Guan L, Liu Q, Zhang Y (2013) Asdbased balanced-lethal system in attenuated Edwardsiella tarda to express a heterologous antigen for a multivalent bacterial vaccine. Fish Shellfish Immunol 34: 1188-1194

* Yang M, Lv Y, Xiao J, Wu H and others (2012) Edwardsiella comparative phylogenomics reveal the new intra/interspecies taxonomic relationships, virulence evolution and niche adaptation mechanisms. PLOS ONE 7:e36987

*Yang M, Shao S, Xiao J, Wang Q, Zhang Y (2013) Phylogenetic investigation of Edwardsiella tarda with multilocus sequence typing (MLST) and pulsed field gel electrophoresis (PFGE) typing methods. Aquaculture 410-411: 79-85

Kang W, Wang L, Zhang L, Qu J, Wang Q, Zhang Y (2015) An invasive and low virulent Edwardsiella tarda esrB mutant promising as live attenuated vaccine in aquaculture. Appl Microbiol Biotechnol 99:1765-1777

*Yin K, Wang Q, Xiao J, Zhang Y (2017) Comparative proteomic analysis unravels a role for EsrB in the regulation of reactive oxygen species stress responses in Edwardsiella piscicida. FEMS Microbiol Lett 364:fnw269

* Yu JH, Han JJ, Park KS, Park KH, Park SW (2009) Edwardsiella tarda infection in Korean catfish, Silurus asotus, in a Korean fish farm. Aquacult Res 41:19-26

* Zhang M, Wu H, Li X, Yang M and others (2012) Edwardsiella tarda flagelar protein FlgD: a protective immunogen against edwardsiellosis. Vaccine 30:3849-3856

Zhu ZC, Shi XG, Zhang SJ, Jiang GJ and others (2006) The pathogenic bacteria of the ascites in Japanese flounder (Paralichthys olivaceus). Fish Sci 25:325-329

Submitted: December 13, 2017; Accepted: August 20, 2018 Proofs received from author(s): September 20, 2018 